Egyptian Journal of Aquatic Biology \& Fisheries

Zoology Department, Faculty of Science,

Ain Shams University, Cairo, Egypt

ISSN $1110-6131$

Vol. 25 (5):919 - 932 (2021)

www.ejabf.journals.ekb.eg

\title{
Protozooplankton combined with magnetic-EDTA@chitosan nanocomposite as a novel system for fish farms wastewater remediation
}

\author{
Amr B. Mostafa ${ }^{{ }^{*}}$, Abdel Halim A. Saad ${ }^{1}$, Ahmed M. Azzam ${ }^{2}$, \\ Mansour G. Ibrahim ${ }^{3}$, Ashraf M. El Saeed ${ }^{4}$, Magdy T. Khalil ${ }^{1}$ \\ 1- Department of Zoology, Faculty of Science, Ain-Shams University, Cairo, Egypt. \\ 2- Department of Environmental Research, Theodor Bilharz Research Institute, Egypt. \\ 3- Zoology Department, Faculty of Science, Menoufia University, Menofia, Egypt. \\ 4- Petroleum Applications Department, Egyptian Petroleum Research Institute, Egypt.
}

*Corresponding Author: amrbayoumy@sci.asu.edu.eg

\section{RTICLE INFO}

Article History:

Received: Oct. 19, 2021

Accepted: Nov. 9, 2021

Online: Nov. 30, 2021

\section{Keywords:}

Fish farms,

Wastewater,

Protozooplankton,

Nanocomposite,

Heavy metals,

Magnetic

Chitosan.

\section{ABSTRACT}

In Egypt, most fish farms use water of agricultural drainage originated from agricultural activities that may contaminate farmed fish. This work was conducted to assess a novel wastewater treatment using combined protozooplankton with magnetic-EDTA@chitosan nanocomposite (ME@CS NC), to dwell with high concentrations of heavy metals and ammonia. A highly significant reduction $(p<0.01)$ was observed in the concentrations of $\mathrm{Pb}, \mathrm{Mn}, \mathrm{Al}$ and $\mathrm{Cd}$ on applying the treatment. The estimated decrease percentages were 99.9, 99.6, 98.8 and 93.3, respectively, whereas Ni showed a reduction of $90.3 \%$. Simultaneously, ammonia in wastewater was significantly reduced $(p<0.01)$. Water environmental parameters of EC, $\mathrm{pH}, \mathrm{TDS}$, and $\mathrm{NO}_{2}$ were reduced by $2.4,3.7,7.4$, and $43.3 \%$, respectively, while $\mathrm{PO}_{4}$, and $\mathrm{NH}_{3}$ were reduced by 76.7 and $94.4 \%$, respectively. Moreover, $\mathrm{COD}$, nitrite, nitrate and phosphate physicochemical parameters were significantly reduced $(p<0.05)$, by 41.4 , $54.9,63.3,64.4 \%$, respectively. Hence, the combined treatment of ME@CS nano-composite and protozooplankton is recommended to be implemented in semi-intensive and modern intensive aquaculture systems to manage less water consumption and attain healthy fish for human consumption.

\section{INTRODUCTION}

Aquaculture has been known in Egypt for a long time, but lately, modern methods have been implemented to maximize its production (Shaalan et al., 2018). The Egyptian aquaculture sector has expanded over the last two decades because of a model shift from traditional extensive to semi-intensive and modern intensive aquaculture systems (FAO, 2020).

Therefore, aquaculture production in Egypt has witnessed a vast growth; production elevated from 139,389 tons in 1998 to $1,561,457$ tons in 2018, which is $71 \%$ of the total aquaculture manufacture in Africa (FAO, 2020). The fisheries and aquaculture sector are essential to improve food security and human nutrition having an increasingly important role in fighting hunger, as articulated in the 2030 agenda. People have never consumed as much fish as they do today, with global fish consumption being doubled since 1960s (FAO, 2018). Egypt's aquaculture industry has grown rapidly since 1998 because of the Egyptian government's consistent and 
cumulative interventions over the years, as well as growing a private sector-driven investment (Soliman \& Yacout, 2016).

The increasing of fish farming production is needed to develop culture systems and meanwhile manage waste efficiently to limit environmental degradation caused by aquaculture wastes and ensure its sustainability (Dauda $\boldsymbol{e t}$ al., 2019). Most fish farms in Egypt use water from agriculture drainage. The used water is an outcome of agricultural activities identified as sources of pesticide residues and runoff derived fertilizers and metals that may contaminate farmed fish (Khallaf \& Authman, 2018).

Most heavy metals are bound to particles in the sediment, while some quantities are dissolved in water, and hence, can spread widely in the food chains (Khadr, 2005) especially those on top of the food chain (El-Nemeki et al., 2008). Metal ions can be incorporated into food chains and concentrated in aquatic organisms to a level that affect their physiological state (Zhao et. al., 2011).

Heavy metals are considered serious pollutants to aquatic ecosystems due to their long-term persistence, toxicity, bioaccumulation, and bio magnification along the water, sediments, and aquatic food chain causing sublethal effects or loss in fish populations besides being considered as carcinogenic elements (Yi et al., 2011). Cadmium, lead, and chromium exhibit great toxicity even at lower levels (Jaishankar et al., 2016).

Poor water quality in fish farms is usually triggered by fish farmers who have inadequate knowledge and skills on proper pond management (Ngugi et al., 2007). The excessive addition of pond inputs (fertilizers either organic (manure) or inorganic and fish feeds) influence both the chemical and physical balances in water (Hossain et al., 2011).

The presence of various inorganic and organic pollutants in aquatic streams has already increased because of industrialization and urbanization (Sarkar and Adhikari, 2018). Protozooplankton are aquatic microscopic organisms that have developed excellent survival strategies, which help them tolerate environmental stresses. Moreover, the biodegradation ability of such protozoan organisms serves as suitable candidate to be used in environmental biotechnology and clearing effluents. Therefore, they can act as natural bio-control in complex ecological systems (Syed $\boldsymbol{e t}$ al., 2019). Protozooplankton is an important component of the aquatic microbial food webs and its composition, density, and distribution that reflect the chemical, physical, and biological aspects of the environment (Bagatini, et al., 2013).

Nanoparticles have a great potential to be used in wastewater treatment. Its unique characteristic of having high surface area can be used efficiently for removing toxic metal ions, disease causing microbes, organic and inorganic solutes from water. Various classes of nano-materials are also proved to be efficient for water treatment, such as metal-containing nanoparticles, carbonaceous nano-materials, zeolites and dendrimers (Pranjali et al., 2013).

Currently, a special attention has been drawn to the environmental contamination with heavy metals due to their high toxicity and non-biodegradability. Notably, inefficient ways of managing heavy metal ions in wastewater may cause long-term risk to both the ecosystem and humans. Effluents containing heavy metal ions are widely discharged from industrial process, such as electroplating and mining; thus, the ions need to be removed before being discharged into water to protect human health and environment (Morsi et al., 2018).

The fishery industry faces a huge economical loss caused by hazardous and heavy metals in such waters leading to growth retardation and fish death. In 
aquaculture, nanotechnology has core applications for water treatment to provide favorable and safe habitat for fish breeding (Shah \& Mraz, 2020).

Chitosan is generally recognized as safe (GRAS) by the US FDA (2001). Chitosan has been widely used in water treatment to eliminate heavy metal and radioactive pollutants. Chitosan is a coagulant that is able to capture substances such as colloids and suspended solids in water, and then it would sink or float. Chitosan nano-composite is one of the most effective adsorbents in removing pollutants from the aquatic environments (Divya \& Jisha, 2018).

Nano-spherical necklaces (NSN) of inorganic $\alpha$-Fe core-organic shell and ethylenediaminetetraacetic acid (EDTA) were fabricated for capturing/trappingAs(V) and $\mathrm{Cr}(\mathrm{VI})$ species from water sources. The $\alpha$-Fe core and the dressing shell of EDTA provided numerous active sites for adsorption, which led to $100 \%$ adsorption uptake of these toxic ions. Treated water showed a removal of $>95 \%$ and $94 \%$ of the As (V) and $\mathrm{Cr}(\mathrm{VI})$ species from this water sources using NSN adsorbent. This obtained result could be used as a basis to provide effective and low-cost products for the purification of wastewater resources from toxic metals (Azzam et al., 2017).

The aim of the present work was to fabricate magnetic-EDTA@chitosan (ME@CS) nano-composite as a novel adsorbent and measure its efficiency for treating draining water of fish farms and improve the treatment process by protozooplankton for safety water reuse to provide unconventional water sources.

\section{MATERIALS AND METHODS}

\section{Water samples, collection and analysis}

In the present study, wastewater and fish samples were collected from fish farms in Kafr El-Sheikh Governorate, Egypt. Chemical oxygen demand (COD), $\mathrm{NH}_{3}, \mathrm{NO}_{3}$, and $\mathrm{PO}_{4}$ were detected in collected water at Faculty of Sciences, Ain-Shams University. Chemical composition ( $\mathrm{Al}, \mathrm{Mn}, \mathrm{Fe}, \mathrm{Ni}, \mathrm{Cu}, \mathrm{Cd}$, and $\mathrm{Pb}$ ) of water samples was recorded using Inductively Coupled Plasma Optical Emission Spectroscopy (ICP-OES) (Prodigy High Dispersion ICP, Leeman, USA) in Central Laboratory for Isotope Applications, Egyptian Atomic Energy Authority.

\section{Water protozooplankton examination}

Water protozoan organisms were collected, examined and identified. The wheat media was prepared, providing a nutritive medium for protozooplankton to accelerate the growth rate. Samples were fixed with mercuric chloride and stained with bromophenol blue for examination and enumeration (Bagatini, et al., 2013). The total count of each protozooplankton species was detected and recorded according to the identification keys of Patterson and Hedley (1996).

\section{Synthesis of chitosan nanoparticles}

The chitosan polymer was extracted from Penaeus Japonicus exoskeleton using the procedure of Abd El-Fattah et al. (2016). The resulting chitosan was washed in running tap water till neutrality, rinsed with distilled water, filtered, and then dried at $60^{\circ} \mathrm{C}$ for $24 \mathrm{hrs}$. The chitosan powder after deacetylation was dissolved in $1 \mathrm{M}$ of $\mathrm{HCl}$, and the solution was then stirred for more than $24 \mathrm{hrs}$ until a pure viscous solution of chitosan was gained. Chitosan nanoparticles were prepared by adjusting the $\mathrm{pH}$ of a chitosan solution to 8.0 by adding $\mathrm{NaOH}$, and thereafter the precipitate was washed and dried at $50^{\circ} \mathrm{C}$ for $24 \mathrm{hrs}$ (He et al., 2016).

Synthesis of magnetic-EDTA nanocomposite (ME NC)

The magnetic nanoparticles were synthesized by modified wet chemical reduction technique according to Chaki $\boldsymbol{e t}$ al. (2015) and Azzam et al. (2017). In the synthesis, regarding solution (A), $500 \mathrm{ml}$ of $0.1 \mathrm{M}$ ferric chloride hexa-hydrate $\left(\mathrm{FeCl}_{3} \cdot 6 \mathrm{H}_{2} \mathrm{O}\right)$ 
and $0.05 \mathrm{M}$ sodium ethylenediaminetetraacetic acid (Na-EDTA) were mixed well. Then, solution (B) was prepared using $500 \mathrm{ml}$ of $2.5 \mathrm{M}$ sodium borohydride $\left(\mathrm{NaBH}_{4}\right)$ that was added drop by drop slowly to solution (A) while keeping up vigorous stirring for $2 \mathrm{hrs}$. At the end of this step, a dark colored precipitate formed, the magnetite. The magnetic-EDTA nano-composite was filtered and given multiple wash using distilled water and absolute methanol. The particles were dried in an oven overnight at $50^{\circ} \mathrm{C}($ Scheme 1$)$.

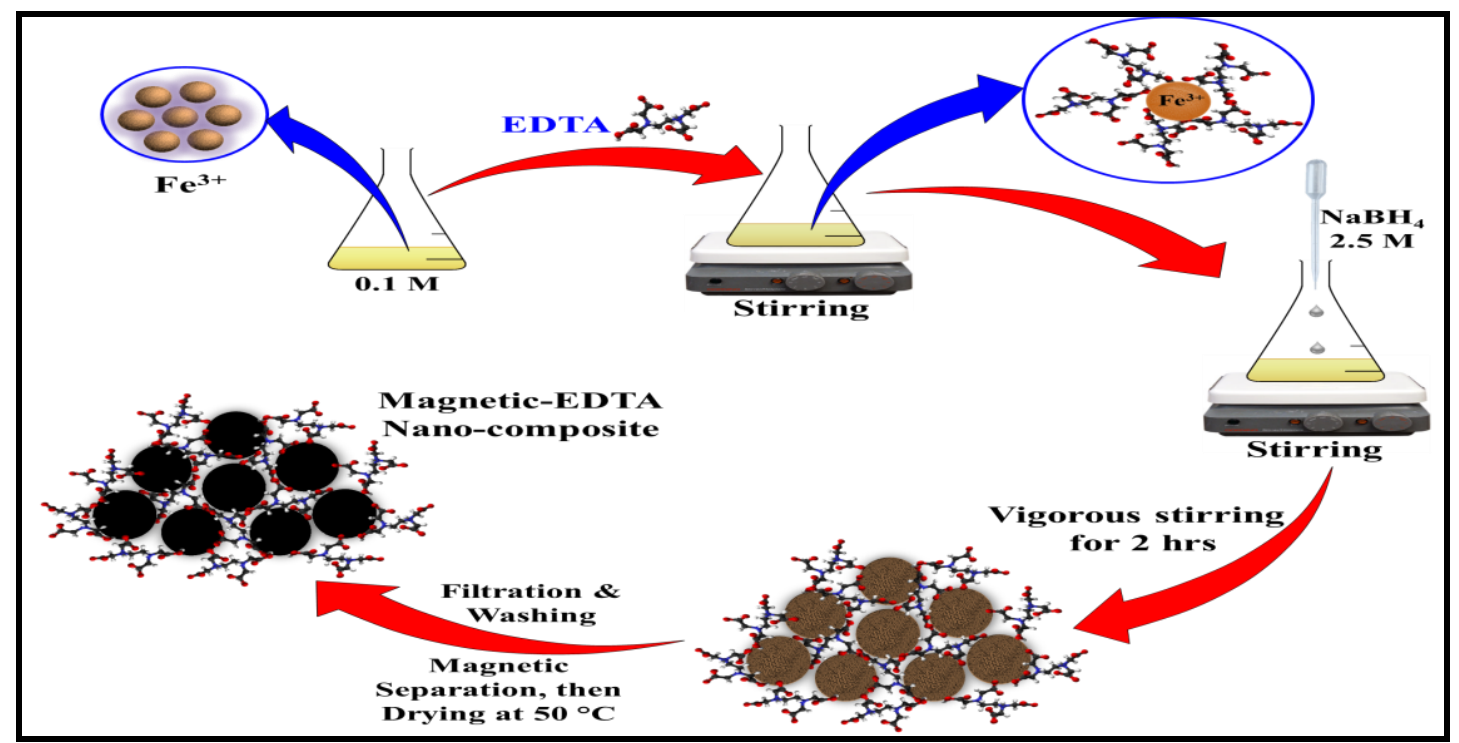

Scheme 1: Synthesis of magnetic-EDTA nano-composite (ME NC).

\section{Preparation of magnetic-EDTA@ chitosan nano-composite (ME@CS NC)}

Magnetic-EDTA@chitosan nano-composite was successfully fabricated by a cross-link reaction between chitosan NPs and ME NC following the procedures of Chen et al (2019). Chitosan NPs were firstly dissolved in acetic acid solution (2.0 wt $\%)$, then ME NC was fully suspended into chitosan solution by ultrasonic irradiation for $30 \mathrm{~min}$. The mixture was continuously mechanically stirred for $2 \mathrm{hrs}$, followed by washing several times with DW to remove unreacted chitosan and separated with magnet. The purified gels were dried in a vacuum oven at $50^{\circ} \mathrm{C}$ for $24 \mathrm{hrs}$ (Scheme 2). 


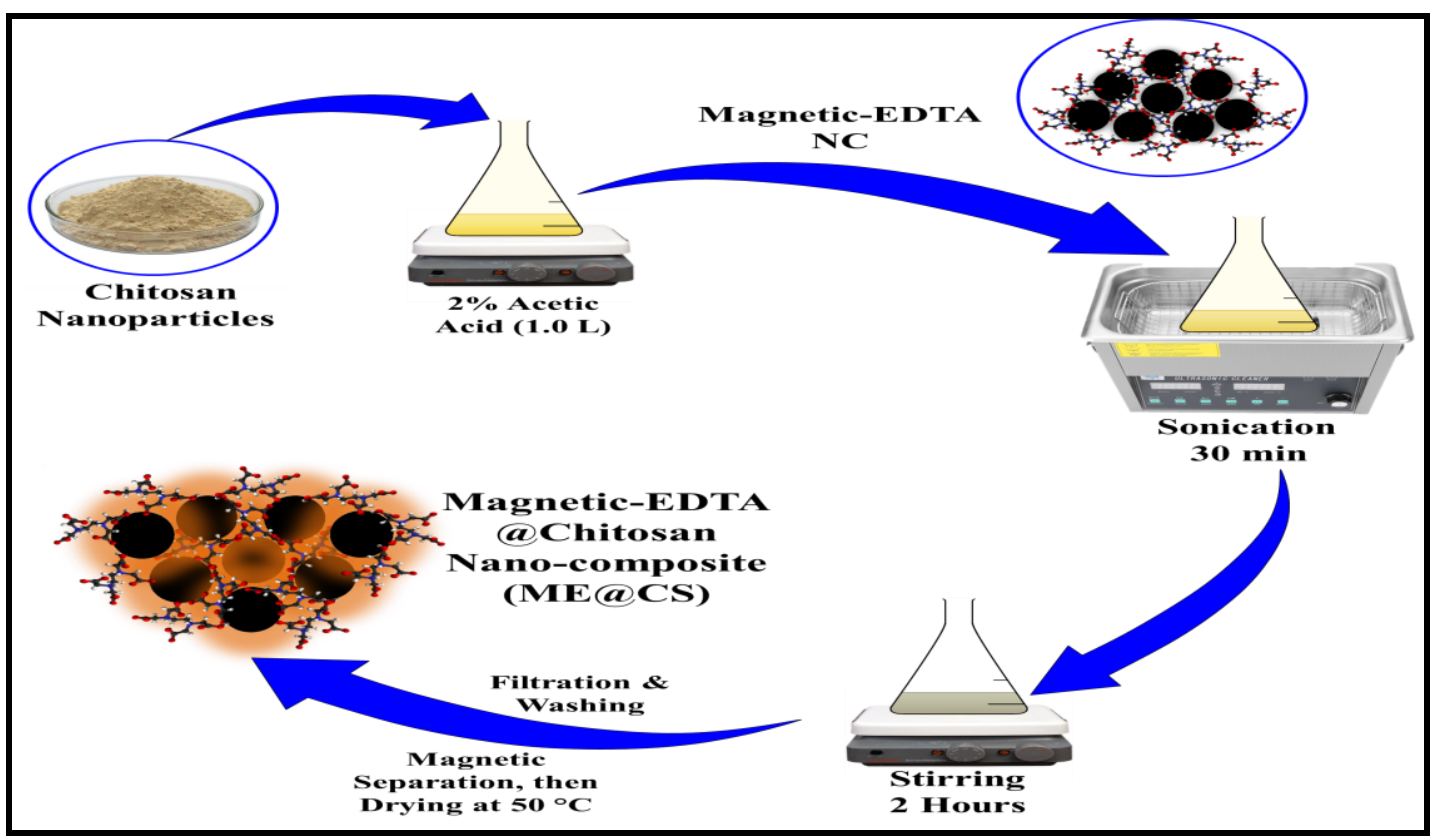

Scheme 2: Preparation of magnetic-EDTA@Chitosan nanocomposite (ME@CS).

\section{Characterization of synthesized nanomaterials}

The structural characterization of the prepared nanomaterials was characterized with the help of multiple techniques. The surface morphology of nanomaterials was identified using a scanning electron microscopy (SEM) (JEOL JSM-5600). The particle size of the resulting nanomaterials was analyzed using transmission electron microscopy (TEM) (EM 208S Philips, Netherlands) connected to a high-resolution imaging system. Fourier Transform Infrared Spectroscopy (FTIR) analysis was carried out to Chitosan NPs; Magnetic-EDTA NC and ME@CS NC were used to identify the functional groups by using Thermo Scientific Nicolet iS10 FTIR spectrometer via the $\mathrm{KBr}$ pressed disc method, with a range starting from 400 to 4000 $\mathrm{cm}^{-1}$ wave numbers.

Combination of protozooplankton and ME@CS nanocomposite to treat polluted drainage water in fish farm

After determining the optimum dose and time of protozooplankton wheat culture and ME@CS nano-composite for maximum removal of some pollutants, the combined treatment for wastewater was carried out. The concentrations of toxic heavy metal ions ( $\mathrm{Al}, \mathrm{Mn}, \mathrm{Fe}, \mathrm{Ni}, \mathrm{Cu}, \mathrm{Cd}$ and $\mathrm{Pb}$ ) and physico-chemical parameter items ( $\mathrm{pH}, \mathrm{EC}, \mathrm{TDS}, \mathrm{COD}, \mathrm{NH}_{3}, \mathrm{NO}_{2}, \mathrm{NO}_{3}$ and $\mathrm{PO}_{4}$ ) of fish farm water were determined before and after the application of treatment.

\section{RESULTS AND DISCUSSION}

\section{Characteristic features of magnetic@chitosan core-shell nano-composite} (ME@CS)

In the present study, scanning electron microscopy (SEM) images for characteristic features of synthesized nano-composite showed that, chitosan NPs were nonporous, spherical in shape witha smooth surface. While, the obtained magnetite EDTA nano-composite (ME NC) was spherical in shape and nanocrystal in form and aggregates up to $200 \mathrm{~nm}$, assembling large aggregates. However, magnetic EDTAchitosan nanocomposite (ME@CS NC) has a spherical shape but doesn't have an 
identical surface. It possesses some differences and a rough and irregular surface, which indicates particles surface and pores filled with chitosan polymer (Fig.1). Moreover, transmission electron microscopy (TEM) images for characteristic features of the synthesized nano-composite revealed that chitosan NPs were spherically shaped and had a particle size ranging from 55 to $110 \mathrm{~nm}$ with an average size of 80 $\mathrm{nm}$. Most ME NC exhibited spherical shape and had a particle size ranging from 15 to $40 \mathrm{~nm}$ with an average size of $26 \mathrm{~nm}$, while ME@CS NC showed a spheroidal morphology in the range of 40-80 nm with an average size of $60 \mathrm{~nm}$. Meanwhile, Chen et al. (2019) reported that TEM images showed uniformly dispersed $\mathrm{Fe}_{3} \mathrm{O}_{4}$ magnetic particles in good spherical shape with an average diameter of 200-500 nm, which is consistent with the SEM results. After the introduction of CS, the resulting $\mathrm{Fe}_{3} \mathrm{O}_{4}$-CS composite showed an irregular shape and some $\mathrm{Fe}_{3} \mathrm{O}_{4}$ particles were embedded into the light grey cross-linked CS matrix, which makes the spherical structure of $\mathrm{Fe}_{3} \mathrm{O}_{4}$ somewhat vague. The TEM pattern of $\mathrm{Fe}_{3} \mathrm{O}_{4}-\mathrm{CS}$ appeared similar to that of $\mathrm{Fe}_{3} \mathrm{O}_{4}$-CS/EDTA (Fig.2). However, Asgari et al. (2020) synthesized nonuniform surface of ME@CS NC in the range of 40.2-55.5 nm with good porosity and relatively uniform distribution throughout the surface.

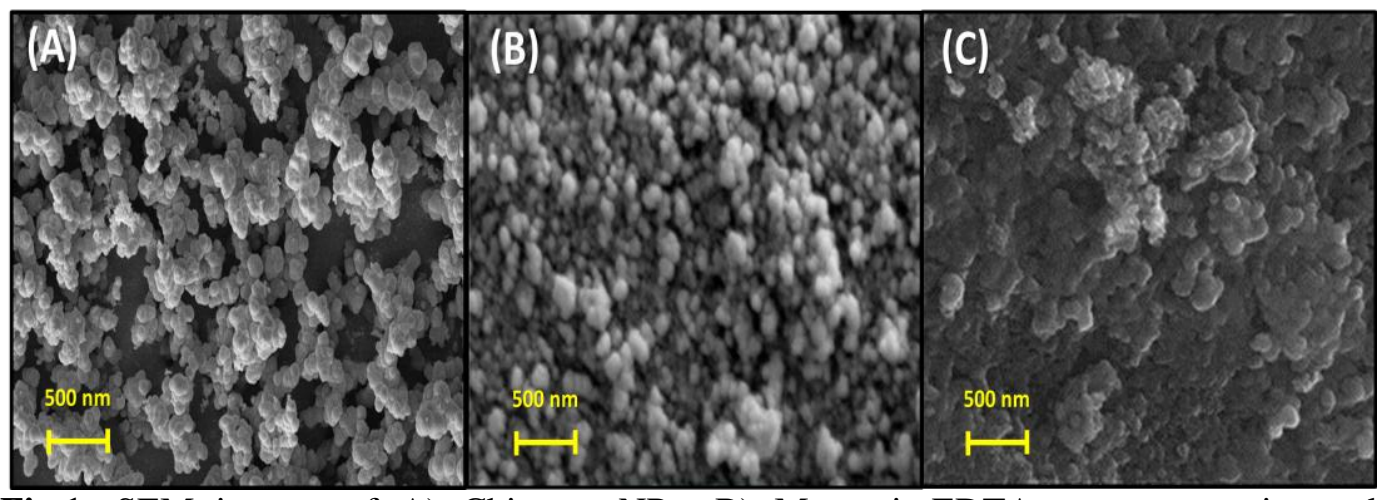

Fig.1: SEM images of A) Chitosan NPs; B) Magnetic-EDTA nano-composite and C) Magnetic-EDTA@Chitosan nano-composite

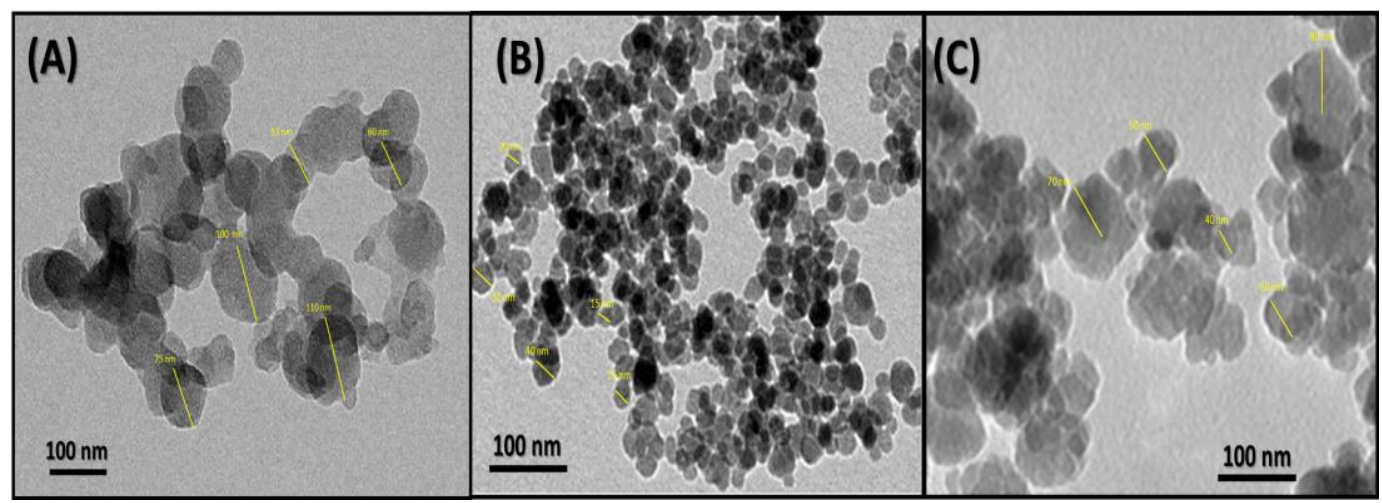

Fig.2: TEM images of A) Chitosan NPs; B) Magnetic-EDTA nano-composite and C) Magnetic-EDTA@Chitosan nano-composite 


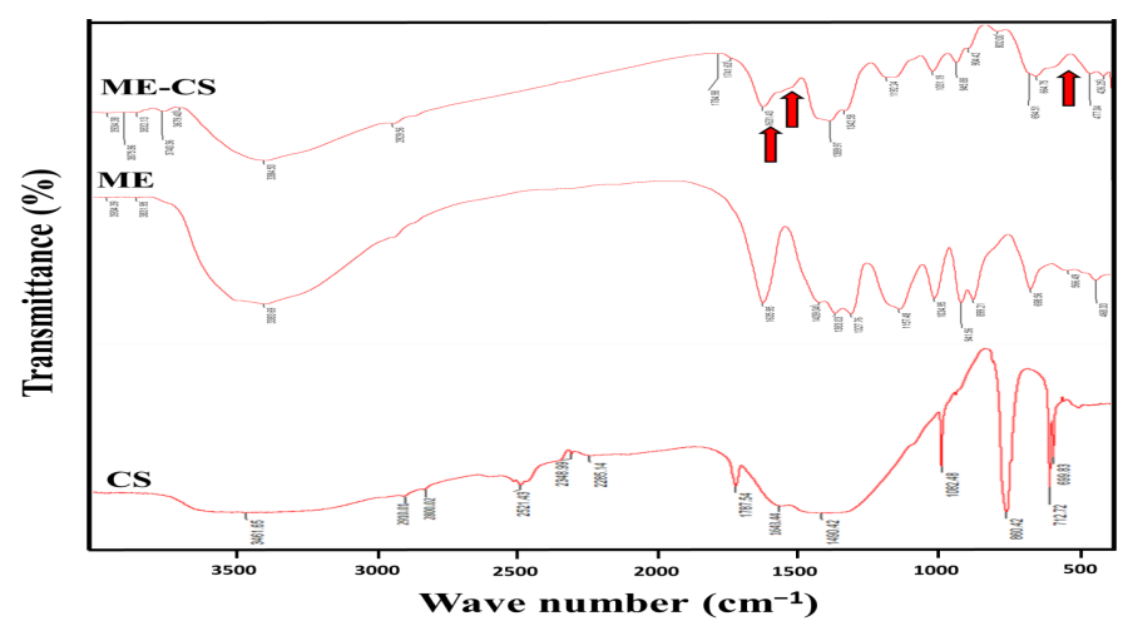

Fig. 3: FTIR spectrum of chitosan nanoparticles (CS); Magnetic-EDTA nano-composite (ME), and Magnetic-EDTA@Chitosan nanocomposite (ME@CS)

In the current study, the Fourier transforms infrared (FTIR) spectroscopy for chitosan NPs, ME NC and ME@CS NC showed that the successful combination between chitosan NPs and ME NC was obviously enhanced, where the peaks were determined at $1631 \mathrm{~cm}^{-1}$ (stretching vibration of carbonyl group in $-\mathrm{COO}^{-}$and amide bond) and $1565 \mathrm{~cm}^{-1}$ (N-H bending vibration of amide). This indicates the successful formation of amide bond between the amino group of CS and carboxyl group of magnetic EDTA NC through an amidation reaction. Moreover, the characteristic peak at around $1389 \mathrm{~cm}^{-1}$, from stretching vibration of $\mathrm{C}-\mathrm{O}$ in $-\mathrm{COO}^{-}$, further confirmed the introduction of carboxyl group of EDTA to CS (Chen et al., 2019). However, new broad absorption band in the range of $694-426 \mathrm{~cm}^{-1}$ appeared in the FTIR spectra of Fe-O-CS NC due to formation of O-Fe-O bond. In addition, the peaks of $\mathrm{C}=\mathrm{O},-\mathrm{NH}_{2}, 3^{\prime}-\mathrm{OH}$, and $5^{\prime}-\mathrm{OH}$ groups were found due to hydrogen bonds between chitosan and $\mathrm{Fe}_{3} \mathrm{O}_{4}$ (Guo et al., 2010; Asgari et al., 2020) (Fig.3).

\section{Treatment of fish farms wastewater using protozooplankton}

Table (1) represents the water parameters of fish farm wastewater treated with $1 \%$ of protozooplankton wheat culture and incubated for $48 \mathrm{hrs}$. Water environmental parameters $\left(\mathrm{NO}_{3}, \mathrm{pH}, \mathrm{NO}_{2}, \mathrm{PO}_{4}\right.$, and $\left.\mathrm{NH}_{3}\right)$ were reduced by 1.1, 1.2, 6.7, 27.8, and $47.2 \%$. However, heavy metals $(\mathrm{Cd}, \mathrm{Al}, \mathrm{Mn}$, and $\mathrm{Pb}$ ) were removed with 6.8, 20.0, 28.4, and $29.1 \%$, while $\mathrm{Ni}$ and $\mathrm{Fe}$ were reduced by 68.3 and $43.0 \%$. Whereas Weisse et al. (2021) demonstrated that improved estimates of peritrich ingestion and clearance rates further emphasize the significance of protozooplankton for the water purification process.

\section{Effect of ME@CS nano-composite concentration}

In this study, the effect of concentration $0.5 \mathrm{~g} / \mathrm{L}$ of ME@CS NC on the removal of heavy metals from fish farm wastewater after an exposure of $60 \mathrm{~min}$ and $\mathrm{pH} 7.0$ recorded high removal percentages with values of 99.9, 99.5, 99.3 and 99.1\% for $\mathrm{Al}$, $\mathrm{Pb}, \mathrm{Cd}$ and $\mathrm{Mn}$ ions, respectively. However, $\mathrm{Ni}, \mathrm{Fe}$ and $\mathrm{Cu}$ ions were removed recording removal percentages of 70.8, 65.0 and 64.2\%, respectively. For Fe, Ni and $\mathrm{Cu}$ ions, they were reduced significantly $(p<0.05)$ at concertation $0.5 \mathrm{~g} / \mathrm{L}$ (Fig. 4). Similarly, Yuan et al. (2021) recorded the adsorption capacity of Co(II) onto the $\mathrm{Fe}_{3} \mathrm{O}_{4} @ \mathrm{CS}$-EDTA and still retained $84.5 \%$ of the capacity of the fresh adsorbent, indicating that $\mathrm{Fe}_{3} \mathrm{O}_{4} @ \mathrm{CS}$-EDTA can be considered a promising recyclable adsorbent to remove heavy-metal ions from wastewater. 
Table 1: Water parameters of fish farm wastewater treated with $1 \%$ wheat culture protozooplankton

\begin{tabular}{|c|c|c|c|}
\hline Parameter & Before & After & Accepted value \\
\hline $\mathbf{p H}$ & 8.2 & 8.1 & $5.0-9.0^{\#}$ \\
\hline $\mathbf{E C}$ & 4.1 & 4.1 & $\mathrm{~ms} / \mathrm{cm}$ \\
\hline TDS & 2.7 & 2.7 & $<1.0 \mathrm{~g} / \mathrm{L}^{\#}$ \\
\hline COD & 29 & 34 & $10-50 \mathrm{mg} / \mathrm{L}^{\#}$ \\
\hline NH $_{3}$ & 0.36 & 0.19 & $<0.1 \mathrm{mg} / \mathrm{L}^{\#}$ \\
\hline Nitrite & 3.0 & 2.8 & $<0.1 \mathrm{mg} / \mathrm{L}^{\#}$ \\
\hline Nitrate & 0.91 & 0.90 & $<50 \mathrm{mg} / \mathrm{L}^{\#}$ \\
\hline Phosphate & 0.90 & 0.65 & $<0.1 \mathrm{mg} / \mathrm{L}^{\#}$ \\
\hline $\mathbf{A l}$ & 78.89 & 63.12 & $<50 \mathrm{ppb}$ \\
\hline Mn & 1.41 & 1.01 & $<10 \mathrm{ppb}$ \\
\hline Fe & 75.8 & 43.2 & $<500 \mathrm{ppb}^{\# \# \#}$ \\
\hline $\mathbf{N i}$ & 9.94 & 3.15 & $<6.0 \mathrm{ppb}^{\# \#}$ \\
\hline $\mathbf{C u}$ & 11.86 & 7.60 & $<0.2-8 \mathrm{ppb}^{\#}$ \\
\hline $\mathbf{C d}$ & 0.118 & 0.110 & $<1.0-7.0 \mathrm{ppb}^{\#}$ \\
\hline Pb & 1.609 & 1.140 & \\
\hline
\end{tabular}

N.B The incubation period: $48 \mathrm{hrs;} \mathrm{ME-CS} \mathrm{nanocomposite:} 0.5 \mathrm{~g} / \mathrm{l}$ contact time: $60 \mathrm{~min}$; agitation rate: $200 \mathrm{rpm}$. ${ }^{*} p<0.05 ;{ }^{* *} p<0.01{ }^{\# \# \#}$ Wedemeyer and Yasutake , 1977, ${ }^{\# \#}$ FAO, 1993, ${ }^{\#}$ Water quality standards/criteria relevant to freshwater aquaculture in Australia (ANZECC, 2000) (Wedemeyer \& Yasutake, 1977; FAO, 1993; ANZECC, 2000)

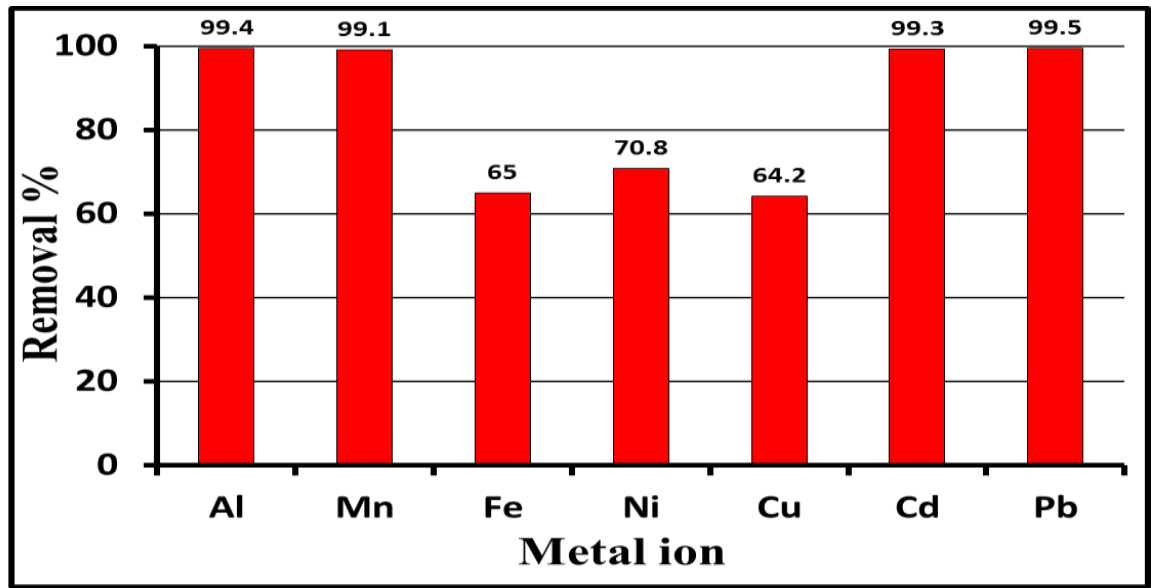

Fig. 4: Removal percentage of heavy metals from fish farm wastewater using ME@CS nanocomposite at concentration $0.5 \mathrm{~g} / \mathrm{l}, \mathrm{pH} 7.7$, and 60 min exposure time

Fig. (5) shows the effect of concentration $0.5 \mathrm{~g} / \mathrm{L}$ of ME@CS NC on physicochemical parameters of fish farm wastewater after an exposure time of $60 \mathrm{~min}$ and $\mathrm{pH}$ 7.0. The ammonia and nitrate showed significant reduction $(p<0.05)$ at concentrationof $0.5 \mathrm{~g} / \mathrm{L}$ of ME@CS NC. However, the COD and phosphate showed non-significant reduction at the same concentration. The reduction percentages of ME@CS NC at concentration of $0.5 \mathrm{~g} / \mathrm{L}$ were 63.3, 57, 28, 21.4 and 11.8 for $\mathrm{NO}_{2}$, $\mathrm{COD}, \mathrm{NH}_{3}, \mathrm{PO}_{4}$ and $\mathrm{NO}_{3}$, respectively. 


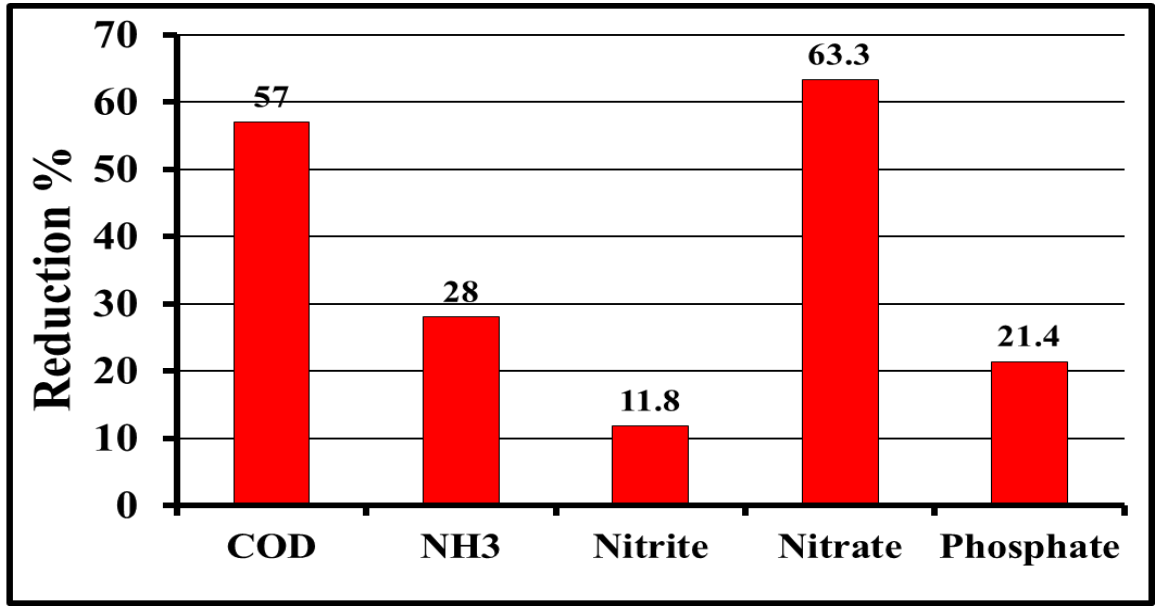

Fig.5: Reduction percentage of physicochemical parameters of fish farm wastewater using ME@CS nano-composite at concentration of $0.5 \mathrm{~g} / 1, \mathrm{pH} 7.7$, and 60 min exposure time

Effect of protozooplankton combination with ME@CS nano-composite on the treatment of polluted drainage water of fish farms

Fish farm wastewater samples were treated by a combination of protozooplankton (1\%) wheat culture for $48 \mathrm{hrs}$ and ME@CS nanocomposite $(0.5$ $\mathrm{g} / \mathrm{L}$ ) for $60 \mathrm{~min}$. Table (2) shows the water parameters of fish farm wastewater treated with $1 \%$ of protozooplankton wheat culture and incubated for $48 \mathrm{hrs}$, then treated with $0.5 \mathrm{~g} / \mathrm{L}$ of ME@CS nano-composite for another one hour.

The ammonia showed highly significant reduction $(p<0.01)$ after the application of the combined treatment. Meanwhile, other physicochemical parameters, such as COD, nitrite, nitrate and phosphate recorded significant reduction $(p<0.05)$. However, water environmental parameters, such as EC, $\mathrm{pH}, \mathrm{TDS}$, and $\mathrm{NO}_{2}$ were reduced by $2.4,3.7,7.4$, and $43.3 \%$, while $\mathrm{COD}, \mathrm{NO}_{3}, \mathrm{PO}_{4}$, and $\mathrm{NH}_{3}$ were reduced by 51.7, 53.8, 76.7, and 94.4\% (Fig.6).

Meanwhile, the heavy metal $(\mathrm{Al}, \mathrm{Mn}, \mathrm{Cd}$ and $\mathrm{Pb})$ concentrations recorded highly significant reduction $(p<0.01)$ after implementation of the combined treatment while $\mathrm{Fe}$ and $\mathrm{Ni}$ showed significant reduction $(p<0.05)$. On the other hand, the reduction percentage of the $\mathrm{Cu}$ was moderate. Moreover, the removal percentages recorded for $\mathrm{Cu}$ and $\mathrm{Fe}$ were 30.0 and $60.9 \%$, while $\mathrm{Ni}, \mathrm{Cd}, \mathrm{Al}, \mathrm{Mn}$ and $\mathrm{Pb}$ were reduced by $90.3,93.3,98.8,99.7$, and $99.9 \%$, respectively. This finding may be attributed to the high level of water $\mathrm{pH}$ leading to low reduction of $\mathrm{Cu}$ ions, where the optimum removal value of $\mathrm{Cu}$ was at the acidic pH of 4.0 (Saad et al., 2020).

Treatment of polluted drainage water of fish farm using ME@CS nanocomposite followed by protozooplankton

Table (3) exhibits the water parameters of El-Shakhlopa (Sidi Salem) fish farm wastewater treated with $0.5 \mathrm{~g} / \mathrm{L}$ of ME@CS nano-composite for one hour, then treated with $1 \%$ of protozooplankton wheat culture and incubated for $48 \mathrm{hrs}$.

Ammonia recorded highly significant reduction $(p<0.01)$ after the previously mentioned combined treatment, while nitrite, nitrate and phosphate showed a significant reduction $(p<0.05)$. However, water environmental parameters such as $\mathrm{pH}$, EC, TDS, and COD were reduced by $2.4,2.4,3.7$, and 41.4\%, while $\mathrm{NO}_{3}, \mathrm{NO}_{2}, \mathrm{PO}_{4}$, and $\mathrm{NH}_{3}$ were declined by $54.9,63.3,64.4$, and $86.1 \%$ (Fig. 7). Ammonia was 
successfully removed from wastewater by eco-friendly biosorbents bentonitechitosan composite (Yadi et al., 2016).

Table 2: Treatment of polluted drainage water of fish farm using Protozooplankton followed by ME@CS nano-composite

\begin{tabular}{|c|c|c|c|}
\hline Parameter & Before & After & Accepted value \\
\hline $\mathbf{p H}$ & 8.2 & 7.9 & $5.0-9.0^{\#}$ \\
\hline $\mathbf{E C}$ & 4.1 & 4.0 & $\mathrm{~ms} / \mathrm{cm}$ \\
\hline $\mathbf{T D S}$ & 2.7 & 2.5 & $<1.0 \mathrm{~g} / \mathrm{L}^{\#}$ \\
\hline $\mathbf{C O D}$ & 29 & $14^{*}$ & $<-50 \mathrm{mg} / \mathrm{L}^{\#}$ \\
\hline $\mathbf{N H}_{\mathbf{3}}$ & 0.36 & $0.02^{* *}$ & $<0.1 \mathrm{mg} / \mathrm{L}^{\#}$ \\
\hline Nitrite & 3.0 & $1.7^{*}$ & $<0.1 \mathrm{mg} / \mathrm{L}^{\#}$ \\
\hline Nitrate & 0.91 & $0.42^{*}$ & $<50 \mathrm{mg} / \mathrm{L}^{\#}$ \\
\hline Phosphate & 0.90 & $0.21^{*}$ & $<0.1 \mathrm{mg} / \mathrm{L}^{\#}$ \\
\hline $\mathbf{A l}$ & 0.081 & $0.001^{* *}$ & $<50 \mathrm{ppb}$ \\
\hline $\mathbf{M n}$ & 60.31 & $0.16^{\text {\#**}}$ & $<10 \mathrm{ppb}$ \\
\hline $\mathbf{F e}$ & 1387 & $542^{*}$ & $<1000 \mathrm{pppb}^{\# \#}$ \\
\hline $\mathbf{N i}$ & 10.4 & $1.01^{*}$ & $<6.0 \mathrm{ppb}^{\# \# \#}$ \\
\hline $\mathbf{C u}$ & 4.57 & 3.20 & $<0.2-8 \mathrm{ppb}^{\#}$ \\
\hline $\mathbf{C d}$ & 0.015 & $0.001^{* *}$ & $<1.0-7.0 \mathrm{ppb}^{\#}$ \\
\hline $\mathbf{P b}$ & 1.609 & $0.001^{* *}$ & $60 \mathrm{mg}$ \\
\hline
\end{tabular}

N.B: The incubation period: 48 hrs; ME-CS nano-composite: $0.5 \mathrm{~g} / \mathrm{l}$ contact time: $60 \mathrm{~min}$; agitation rate: $200 \mathrm{rpm}$. ${ }^{*} p<0.05 ;{ }^{* *} p<0.01{ }^{\# \# \#}$ Wedemeyer and Yasutake , 1977, ${ }^{\text {\#\# }}$ FAO, 1993, "Water quality standards/criteria relevant to freshwater aquaculture, in Australia (Wedemeyer \& Yasutake, 1977; FAO, 1993; ANZECC, 2000).

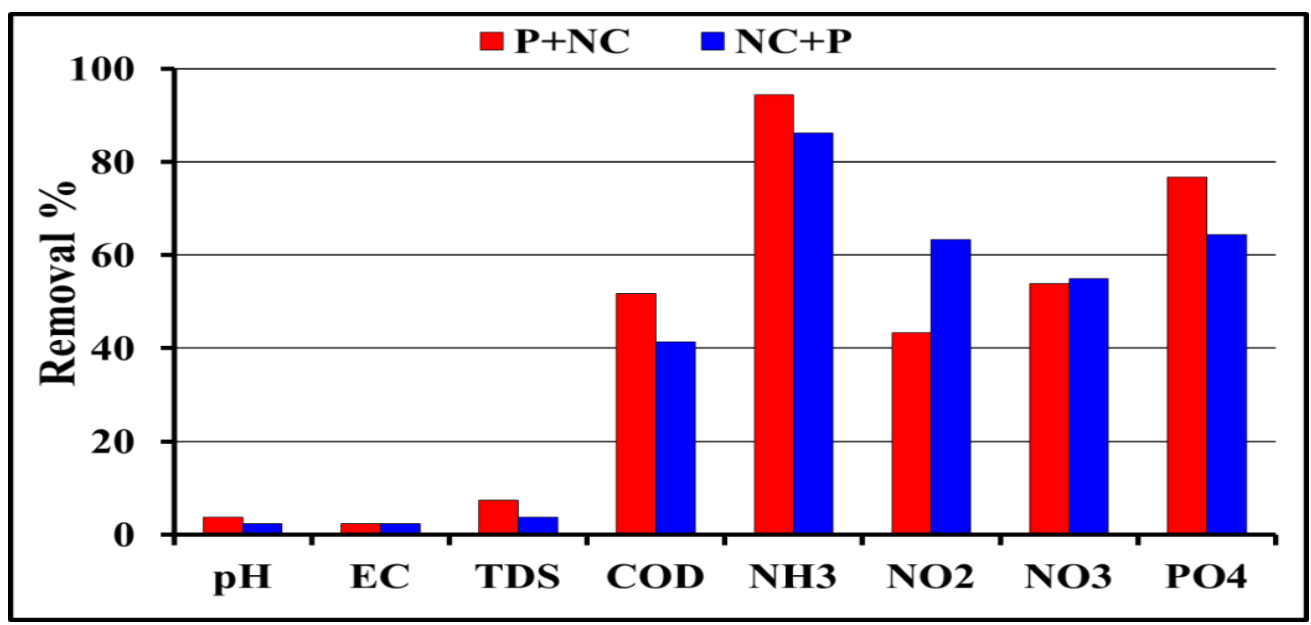

Fig. 6: Removal percentages of environmental parameters of fish farm wastewater using protozooplankton followed by ME@CS nanocomposite (P+NC) and ME@CS nanocomposite followed by protozooplankton $(\mathrm{NC}+\mathrm{P})$.

For heavy metals removal, the above-mentioned treatment removed metals as $\mathrm{Pb}, \mathrm{Mn}, \mathrm{Cd}$, and $\mathrm{Ni}$ with a highly significant reduction $(p<0.01), \mathrm{Al}$ and $\mathrm{Fe}$ presented a significant one $(p<0.05)$, while $\mathrm{Cu}$ showed no significant decline. Moreover, heavy metals such as $\mathrm{Cu}$ and $\mathrm{Fe}$ were removed with 16.8 and $43.5 \%$, while $\mathrm{Al}, \mathrm{Ni}, \mathrm{Cd}, \mathrm{Mn}$ and $\mathrm{Pb}$ were reduced by 84.0, 87.5, 93.3, 99.6, and 99.9\% (Fig. 7). The superior adsorption performance of magnetic chitosan could be attributed to the electrostatic interaction and ion exchange between target pollutants and the grafted cationic polymer (Zheng et al., 2021).

Owing to its high adsorption capacity and rapid separation, ME@CS nanocomposite has great potential for practical application in fish farms wastewater 
treatment. The present results could potentially satisfy the increasing need for the purification of wastewater resources contaminated with toxic metals.

Table 3: Treatment of polluted drainage water of fish farm using ME@CS nano-composite followed by protozooplankton

\begin{tabular}{|c|c|c|c|c|}
\hline Parameter & Before & After & Removal \% & Accepted value \\
\hline pH & 8.2 & 8.0 & 2.4 & $5.0-9.0^{\#}$ \\
\hline EC & 4.1 & 4.0 & 2.4 & $\mathrm{~ms} / \mathrm{cm}^{\#}$ \\
\hline TDS & 2.7 & 2.6 & 3.7 & $<1.0 \mathrm{~g} / \mathrm{L}^{\#}$ \\
\hline COD & 29 & 17 & 41.4 & $10-50 \mathrm{mg} / \mathrm{L}^{\#}$ \\
\hline NH $_{3}$ & 0.36 & $0.05^{* *}$ & 86.1 & $<0.1 \mathrm{mg} / \mathrm{L}^{\#}$ \\
\hline Nitrite & 3.0 & $1.1^{*}$ & 63.3 & $<0.1 \mathrm{mg} / \mathrm{L}^{\#}$ \\
\hline Nitrate & 0.91 & $0.41^{*}$ & 54.9 & $<50 \mathrm{mg} / \mathrm{L}^{\#}$ \\
\hline Phosphate & 0.90 & $0.32^{*}$ & 64.4 & $<0.1 \mathrm{mg} / \mathrm{L}^{\#}$ \\
\hline $\mathbf{A l}$ & 0.081 & $0.013^{*}$ & 84.0 & $<50 \mathrm{ppb}$ \\
\hline $\mathbf{M n}$ & 60.31 & $0.24^{* *}$ & 99.6 & $<10 \mathrm{ppb}^{\# \# \#}$ \\
\hline $\mathbf{F e}$ & 1387 & $784^{*}$ & 43.5 & $<500 \mathrm{ppb}^{\# \# \#}$ \\
\hline $\mathbf{N i}$ & 10.4 & $1.3^{* *}$ & 87.5 & $<1000 \mathrm{ppb}^{\#}$ \\
\hline $\mathbf{C u}$ & 4.57 & 3.80 & 16.8 & $<6.0 \mathrm{ppb}^{\# \#}$ \\
\hline $\mathbf{C d}$ & 0.015 & $0.001^{* *}$ & 93.3 & $<0.2-8 \mathrm{ppb}^{\#}$ \\
\hline Pb & 1.609 & $0.001^{* *}$ & 99.9 & $<1.0-7.0 \mathrm{ppb}^{\#}$ \\
\hline
\end{tabular}

(ME@CS nano-composite: $0.5 \mathrm{~g} / \mathrm{L}$ with contact time: $60 \mathrm{~min}$; Protozooplankton: $1 \%$ with incubation: $48 \mathrm{hrs;}$ agitation time: $200 \mathrm{rpm}$ ).

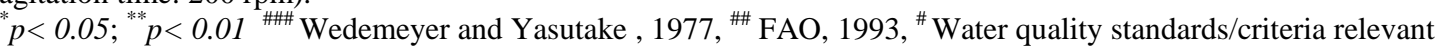
to freshwater aquaculture, in Australia (Wedemeyer \& Yasutake, 1977; FAO, 1993; ANZECC, 2000).

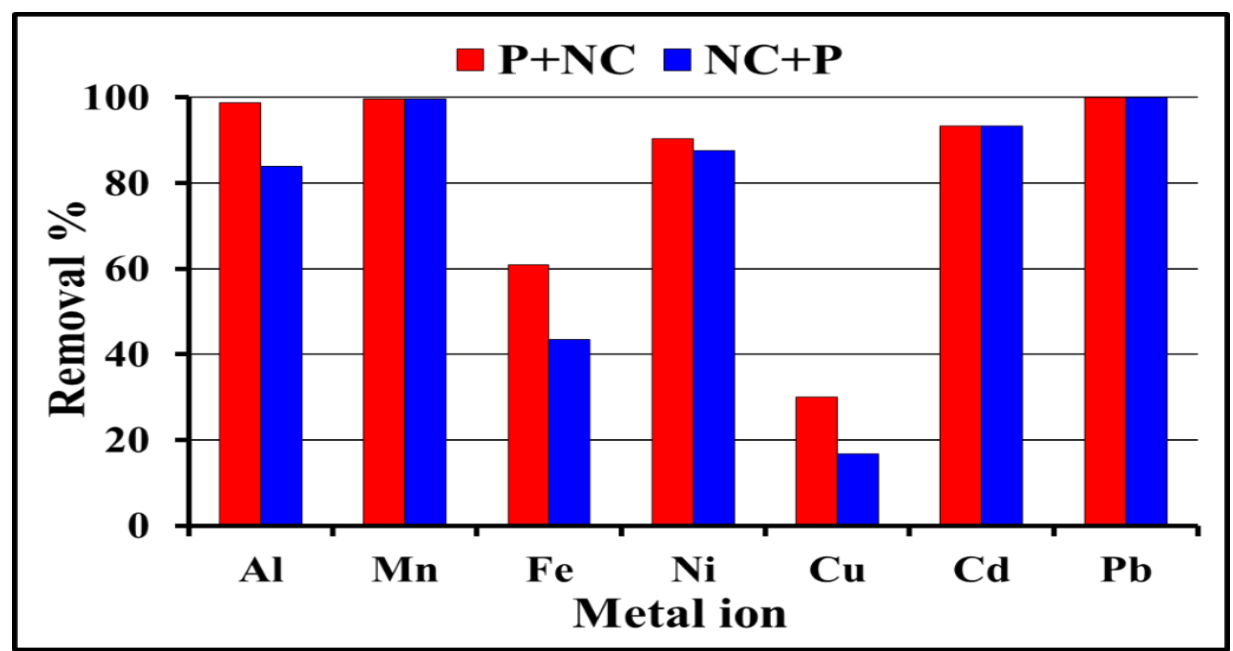

Fig. 7: Removal percentages of heavy metal ions from fish farm wastewater using protozooplankton followed by ME@CS nano-composite $(\mathrm{P}+\mathrm{NC})$ and ME@CS nanocompoite followed by protozooplankton $(\mathrm{NC}+\mathrm{P})$

\section{CONCLUSION}

The present work proved that the combined treatment of protozooplankton and the nano-composite (ME@CS) is able to remove pollutants from fish farm wastewater. The study proved that wheat provided a suitable natural nutritive media to increase the number of protozoan organisms that have the ability to remove some pollutants from the wastewater. It is recommended to use the environmentally safe combined treatment using ME@CS nano-composite and protozooplankton, which showed promising results for the treatment of polluted drainage water used in open fish farms.The usage of ME@CS nano-composite and 
protozooplankton in semi-intensive and modern intensive aquaculture systems would lead to the optimization of water consumption, production of healthy fish and would consequently maintain safe human consumption of fish production.

\section{REFERENCES}

Abd El-Fattah, M.; El Saeed, A.M.; Azzam, A.M.; Abdul-Raheim, A.M. and Hefni, H.H.H. (2016). Improvement of corrosion resistance, antimicrobial activity, mechanical and chemical properties of epoxy coating by loading chitosan as a natural renewable resource. Progress in Organic Coatings Journal, 101: 288-296.

Asgari, E.; Sheikhmohammadi, A. and Yeganeh, J. (2020). Application of the $\mathrm{Fe}_{3} \mathrm{O}_{4}$-chitosan nano-adsorbent for the adsorption of metronidazole from wastewater: Optimization, kinetic, thermodynamic and equilibrium studies. International Journal of Biological Macromolecules, 164: 694-706.

Azzam, A.M.; Shenashen, M.A.; Selim, M.M.; Yamaguchi, H.; El-Sewify, I.M.; Kawada, S. and El-Safty, S.A. (2017). Nanospherical inorganic $\alpha$-Fe coreorganic shell necklaces for the removal of arsenic (V) and chromium (VI) from aqueous solution. Journal of Physics and Chemistry of Solids, 109: 7888 .

Bagatini, I.L.; Spínola, A.L.G.; Peres, B.D.M.; Mansano, A.D.S.; Rodrigues, M.A.A.; Batalha, M.A. and Seleghim, M.H.R. (2013). Protozooplankton and its relationship with environmental conditions in 13 water bodies of the Mogi-Guaçu basin-SP, Brazil. Biota Neotropica, 13: 152-163.

Chaki, S.H.; Malek, T.J.; Chaudhary, M.D.; Tailor, J.P. and Deshpande, M.P. (2015). Magnetite $\mathrm{Fe}_{3} \mathrm{O}_{4}$ nanoparticles synthesis by wet chemical reduction and their characterization. Advances in Natural Sciences: Nanoscience and Nanotechnology, 6(3): 035009.

Chen, B.; Zhao, H.; Chen, S.; Long, F.; Huang, B.; Yang, B. and Pan, X. (2019). A magnetically recyclable chitosan composite adsorbent functionalized with EDTA for simultaneous capture of anionic dye and heavy metals in complex wastewater. Chemical Engineering Journal, 356: 69-80.

Dauda, A.B.; Ajadi, A.; Tola-Fabunmi, A.S. and Akinwole, A.O. (2019). Waste production in aquaculture: Sources, components and managements in different culture systems. Aquaculture and Fisheries, 4(3): 81-88.

Divya, K. and Jisha, M.S. (2018). Chitosan nanoparticles preparation and applications. Environmental Chemistry Letters: 1-12.

El-Nemeki, F.A.; Ali, N.A.; Zeinhom, M.M. and Radwan O.A. (2008). Impacts of different water resources on the ecological parameters and the quality of tilapia production at El-Abbassa fish farms in Egypt. $8^{\text {th }}$ international symposium on tilapia in aquaculture: 491-512.

FAO (1993). Water quality and fish health. EIFAC Technical Paper. No. 54. Rome, FAO. 1993. 59 p.

FAO (2018). The State of World Fisheries and Aquaculture 2018 - Meeting the sustainable development goals. Rome.

FAO (Food and Agriculture Organization of the United Nations) (2020). National Aquaculture Sector Overview. Egypt. National Aquaculture Sector Overview Fact Sheets. Text by Salem AM, Saleh MA. In: FAO Fisheries and Aquaculture Department [online]. Rome: FAO. Cited 11 May 2020. http://www.fao. org/fishery/countrysector/naso_egypt/en. 
Guo, L.; Liu, G.; Hong, R.-Y. and Li, H.-Z. (2010). Preparation and characterization of chitosan poly(acrylic acid) magnetic microspheres. Mar. Drugs, 8: 2212-2222.

He, X.; Li, K.; Xing, R.; Liu, S.; Hu, L. and Li, P. (2016). The production of fully deacetylated chitosan by compression method. The Egyptian Journal of Aquatic Research, 42(1): 75-81.

Hossain, M.K.; Islam, K.T.; Hossain, M.D. and Rahman, M.H. (2011). Environmental impact assessment of fish diseases on fish production. J. Sci. Found., 9:125-131.

Jaishankar, M.; Tseten, T.; Anbalagan, N.; Mathew, B.B. and Beeregowda, K.N. (2014). Toxicity, mechanism and health effects of some heavy metals. Interdisciplinary toxicology, 7(2): 60-72.

Khadr, A.M. (2005). Copper concentrations and phases in polluted surface sediments of Lake Edku, Egypt. Egyptian Journal of Aquatic Research, 31(2): 253-260.

Khallaf, E.A. and Authman, M.M. (2018). Contamination and ecological hazard assessment of heavy metals in freshwater sediments and Oreochromis niloticus (Linnaeus, 1758) fish muscles in a Nile River Canal in Egypt. Environmental Science and Pollution Research, 25(14): 13796-13812.

Morsi, R.E.; Al-Sabagh, A.M.; Moustafa, Y.M.; ElKholy, S.G. and Sayed, M.S. (2018). Polythiophene modified chitosan/magnetite nanocomposites for heavy metals and selective mercury removal. Egyptian Journal of Petroleum, 27(4): 1077-1085.

Ngugi, C.C.; Bowman, J.R. and Omolo, B.O. (2007). A new guide to fish farming in Kenya. Aquaculture Collaborative Res Support Program (ACRSP):1-100

Patterson, D.J. and Hedley, S. (1996). Freeliving Freshwater Protozoa. CRC Press.

Pranjali, G.; Deepa, M. and Nair, A.B. (2013). Nanotechnology in waste water treatment: A review. International Journal of ChemTech Research, 5(5): 2303-2308.

Saad, A.A.; Azzam, A.M.; El-Wakeel, S.T.; Mostaf, B.B. and Abd El-Latif M.B. (2020). Industrial wastewater remediation using Hematite@Chitosan nanocomposite. Egyptian Journal of Aquatic Biology and Fisheries, 24(1):1329.

Sarkar, S. and Adhikari, S. (2018). Adsorption technique for removal of heavy metals from water and possible application in wastewater-fed aquaculture. In Wastewater Management Through Aquaculture, Springer, Singapore: 235251.

Shaalan, M.; El-Mahdy, M.; Saleh, M. and El-Matbouli, M. (2018). Aquaculture in Egypt: insights on the current trends and future perspectives for sustainable development. Rev. Fish. Sci. Aquacult. 26(1):99-110

Shah, B.R. and Mraz, J. (2020). Advances in nanotechnology for sustainable aquaculture and fisheries. Reviews in Aquaculture, 12: 925-942.

Soliman, N.F. and Yacout, D.M. (2016). Aquaculture in Egypt: status, constraints and potentials. Aquaculture international, 24(5): 1201-1227.

Syed, T.; Batool, U.; Aslam, M.; Noreen, Z.; Farheen, I.; Gondal, A. and Bokhari, H. (2019). Bioremediation and decontamination potential of flagellate Poteriospumella sp. Bioremediation Journal, 23(3): 142-153.

US FDA (US Food and Drug Administration) (2001). Center for Food Safety and Applied Nutrition. Office of Premarket Approval. GRAS Notices received in 2001. 
Yadi, M. G.; Benguella, B.; Gaouar-Benyelles, N. and Tizaoui, K. (2016). Adsorption of ammonia from wastewater using low-cost bentonite/chitosan beads. Desalination and Water Treatment, 57(45): 21444-21454

Yuan, D., Liu, W., Wang, J., Cui, J., He, L., Yan, C., \& Li, J. (2021). Facile preparation of EDTA-functionalized magnetic chitosan for removal of co (II) from aqueous solutions. Environmental technology, 42(9), 1313-1325.

Yi, Y.; Yang, Z. and Zhang, S. (2011). Ecological risk assessment of heavy metals in sediment and human health risk assessment of heavy metals in fishes in the middle and lower reaches of the Yangtze River basin. Environmental pollution, 159(10): 2575-2585.

Wedemeyer, G. A., and Yasutake, W. T. (1977). Clinical methods for the assessment of the effects of environmental stress on fish health (Vol. 89). Department of the Interior, Fish and Wildlife Service.

Weisse, T., Jezberova, J., and Moser, M. (2021). Picoplankton feeding by the ciliate Vorticella similis in comparison to other peritrichs emphasizes their significance in the water purification process. Ecological Indicators, 121, 106992.

Zhao, G.; Wu, X.; Tan, X. and Wang, X. (2011). Sorption of heavy metal ions from aqueous solutions: A review. Open Colloid Sci. J., 4:19-31.

Zheng, C., Wu, Q., Hu, X., Wang, Y., Chen, Y., Zhang, S., \& Zheng, H. (2021). Adsorption behavior of heavy metal ions on a polymer-immobilized amphoteric biosorbent: Surface interaction assessment. Journal of Hazardous Materials, 403, 123801.

\section{ARABIC SUMMARY}

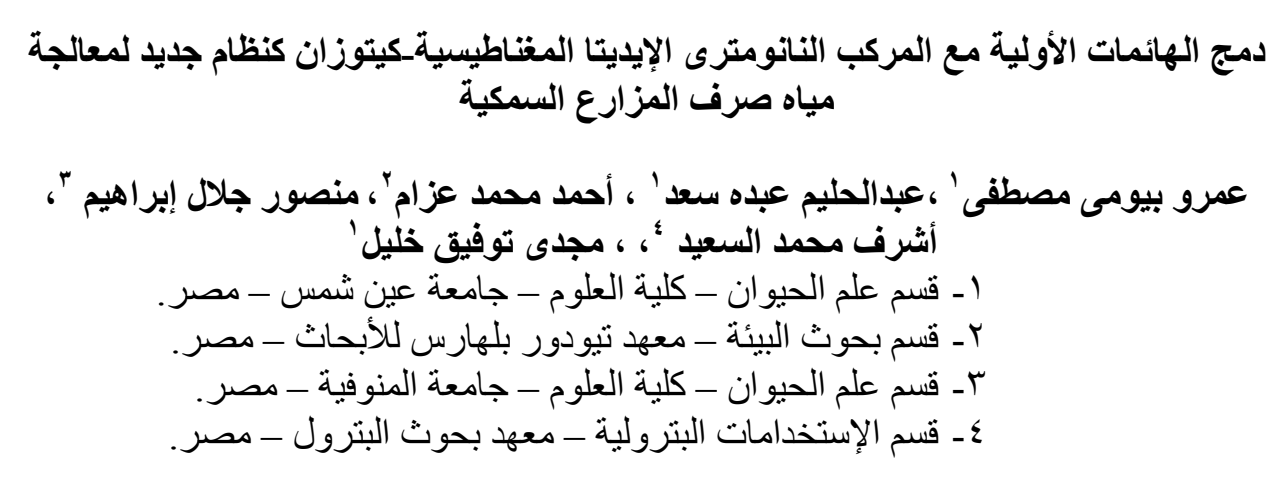

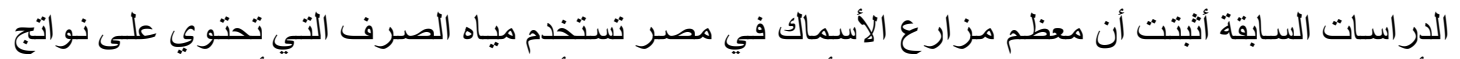

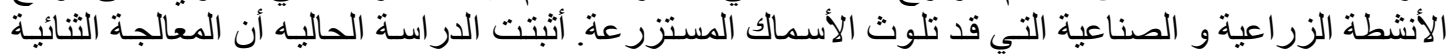

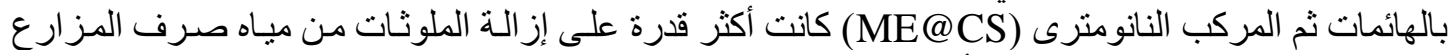

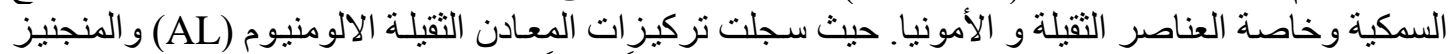

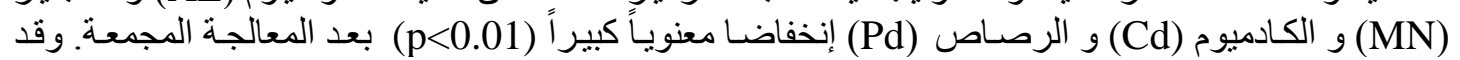

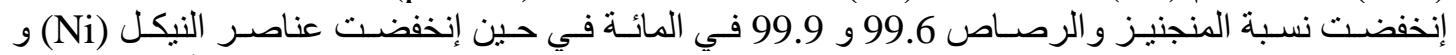

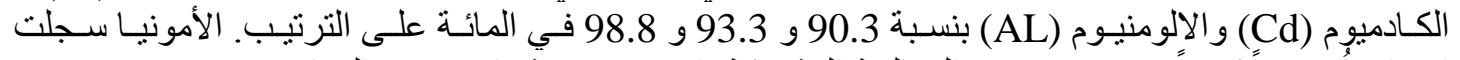

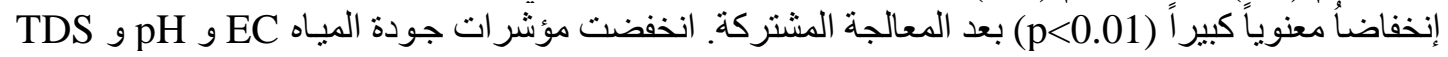

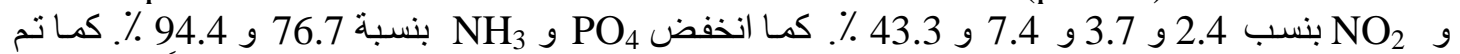

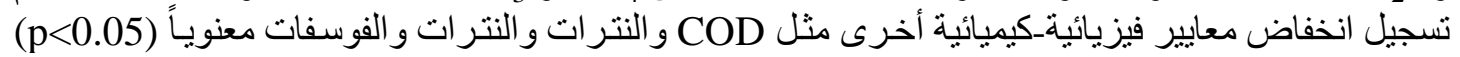

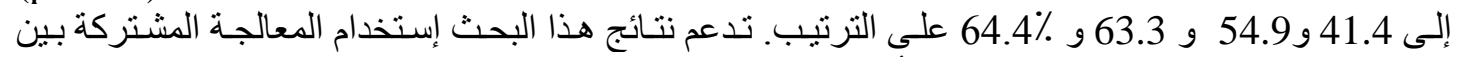

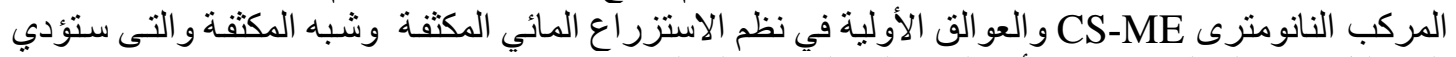

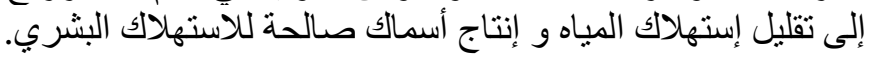

